COLONIC MOTILITY

\title{
Interstitial cells of Cajal are involved in the afferent limb of the rectoanal inhibitory reflex
}

\author{
F de Lorijn, W J de Jonge, T Wedel, J M Vanderwinden, M A Benninga, G E Boeckxstaens
}

Gut 2005;54:1107-1113. doi: 10.1136/gut.2004.051045

See end of article for authors' affiliations

Correspondence to:

Dr G E Boeckxstaens,

Department of

Gastroenterology and

Hepatology, Academic

Medical Centre

Meibergdreef 9, $1105 \mathrm{AZ}$

Amsterdam, the

Netherlands:

g.e.boeckxstaens@

amc.uva.nl

Revised version received

2 March 2005

Accepted for publication

7 March 2005
Background and aims: Interstitial cells of Cajal (ICC) have been shown to be involved in nitrergic neurotransmission of the lower oesophageal sphincter and pylorus. Here we studied the role of ICC and nitric oxide (NO) in the inhibitory neurotransmission of the murine internal anal sphincter (IAS).

Methods: The rectoanal inhibitory reflex, rectal compliance, and relaxation of the isolated IAS to electrical stimulation were measured in controls, $K I T T^{\mathrm{W}} / K I T^{W_{v}}$ mice, and neuronal NO synthase (nNOS) deficient mice. In addition, we evaluated the effect of blockade of nNOS using N-nitro-L-arginine methyl ester. Distribution of nNOS positive neurones and ICC in the IAS was assessed immunohistochemically.

Results: KIT positive ICC were present in a dense network in the IAS of controls but not in $K I T T^{W} / K T^{W_{v}}$ mice. Relaxation of IAS muscle strips induced by electrical stimulation was diminished in $\mathrm{nNOS}^{-1-}$ mice but not in KIT W/KIT ${ }^{W_{v}}$ mice. Blockade of NOS reduced the relaxation of IAS muscle strips in both mice. Relaxation of the IAS to rectal distension was significantly diminished in KIT ${ }^{W} / K I T{ }^{W v}$ mice and nNOS deficient mice. In concert, in vivo blockade of NOS attenuated the relaxation of the IAS in controls. No significant difference in compliance was found.

Conclusion: The inhibitory innervation of the IAS and the rectoanal inhibitory reflex are mediated by NO and the rectoanal inhibitory reflex requires an intact network of ICC in the IAS. Thus both loss of nitrergic innervation and deficiency of ICC lead to impaired anal relaxation and may play an important role in rectal evacuation disorders.
$\mathrm{N}$ ormal defecation depends on the complex interplay between colonic motility, rectal sensation, and anal sphincter function. When stool arrives in the rectum, filling of the rectum leads to stretch of the rectal wall with subsequent triggering of a transient relaxation of the internal anal sphincter (IAS), also called the rectoanal inhibitory reflex (RAIR). Abnormalities in the RAIR have been shown to be involved in defecation disorders and severe constipation, such as in Hirschsprung's disease. ${ }^{12}$

The RAIR is a motor pattern mediated by intrinsic enteric nerves. Previous animal studies have shown that the inhibitory neurones relaxing the IAS mainly release nitric oxide $(\mathrm{NO}) .^{3}{ }^{4}$ Blockade of $\mathrm{NO}$ biosynthesis reduced the relaxation of muscle strips of the IAS and impaired the RAIR. ${ }^{35}$ Recently, evidence was provided that the nitrergic innervation is dependent on the presence of an intact network of interstitial cells of Cajal (ICC). ${ }^{67}$ ICC function as pacemaker cells coordinating the electromechanical activity of the gut. ${ }^{89}$ In addition, ICC located in the muscular layer have been shown to mediate nitrergic neurotransmission in the stomach and lower oesophageal sphincter (LOS). ${ }^{7}$ To what extent ICC are also involved in the nitrergic innervation of the IAS is unknown. Therefore, the present study was designed to evaluate the role of ICC in the nitrergic innervation of the IAS and in the triggering of the RAIR.

\section{MATERIALS AND METHODS}

\section{Animals}

Adult $K I T^{W} / K I T^{W v}$ mice (20-30 g) and their wild-type (KIT $\left.T^{W} /+\right)$ controls, as well as neuronal nitric oxide synthase (nNOS) deficient mice (18-28 g) and their respective wild-type controls (site bred $\mathrm{C} 57 \mathrm{BL} / 6 \mathrm{~J}$ ) were purchased from the Jackson Laboratory (Bar Harbor, Maine, USA). For immunohistochemical studies, transgenic mice were used that carry the KIT W-lacZ allele ("lacZ positive controls"). ${ }^{10-13}$ KIT ${ }^{W-\text { lacZ }} /$ KIT $^{W v}$ lack ICC, ${ }^{14}$ similar to the more extensively studied $K I T^{W} / K I T{ }^{W v}$ animals, ${ }^{915}$ and will be referred to as "ICC deficient animals".

All animals were maintained under controlled conditions and were used at 8-12 weeks of age. Experiments were approved by the Ethical Animal Research Committee of the University of Amsterdam, the Netherlands, and by the Faculty Committee for Use of Laboratory Animals of the Faculté de Médecine, Université Libre de Bruxelles, Belgium.

\section{Immunohistochemistry}

Fresh frozen anorectal specimens of control and KIT ${ }^{W} / K I T^{W v}$ mice were harvested for longitudinal cryosections, while paraformaldehyde fixed specimens of control $\left(K_{1} T^{\text {Wlacz }} /+\right)$ and $K I T^{W \text {-lacZ }} / K I T^{W v}$ mice were harvested for transverse and longitudinal cryosections as well as for whole mount preparations, as described previously. ${ }^{12}$

Whole mounts: preparation and immunohistochemistry

After preincubation with 10\% normal mouse serum, samples were incubated overnight with the KIT goat and the nNOS rabbit antisera (Santa Cruz Biotechnology, Santa Cruz, California, USA) diluted in Tris buffered saline-Triton $\mathrm{X}$ (TBS-TX) containing $1 \%$ normal horse serum (NHS). Samples were then rinsed in TBS, incubated in the dark for one hour at room temperature in TBS containing donkey antirabbit antiserum coupled to FITC (Jackson Immunoresearch Laboratories, West Grove, Pennsylvania, USA) and biotinylated donkey antigoat antiserum (Jackson)

Abbreviations: IAS, internal anal sphincter; ICC, interstitial cells of Cajal; nNOS, neuronal nitric oxide synthase; NO, nitric oxide; RAIR, rectoanal inhibitory reflex; L-NAME, N-nitro-L-arginine methyl ester; LOS, lower oesophageal sphincter; TBS-TX, Tris buffered saline-Triton X; NHS, normal horse serum; NANC, non-adrenergic non-cholinergic; SNP, sodium nitroprusside; ATP, 5'-adenosine triphosphate 
diluted $1 / 200$ and $1 / 100(\mathrm{v} / \mathrm{v})$, respectively, rinsed in TBS, and finally incubated in the dark for one hour at room temperature with streptavidin Texas red (Jackson) diluted $1 / 400(\mathrm{v} / \mathrm{v})$ in TBS. Specimens were then transferred onto a glass slide coated with $0.1 \%$ poly-L-lysine and were cut into two equal parts. Coverslips were mounted with "Slow Fade Light" antifade mounting medium (Molecular Probes, Eugene, Oregon, USA) before viewing on a confocal microscope (MRC 1024; Bio-Rad Laboratories, Hemel Hempstead, Hertfordshire, UK) fitted on an inverted microscope equipped with a Plan-Neofluar $40 \times / 1.3$ oil immersion objective (Axiovert 100; Zeiss, Oberkochen, Germany). As KIT-ir appeared fairly weak in ICC deficient animals with the fluorescent detection system, the more sensitive detection system using peroxidase was additionally applied.

\section{Sections: preparation and immunohistochemistry}

Specimens were fixed overnight in fresh $4 \%$ paraformaldehyde solution in phosphate buffered saline, $\mathrm{pH} 7.4$, at $4^{\circ} \mathrm{C}$, cryopreserved in graded solutions of sucrose (10-30\%), embedded in Tissue-Tek OCT compound (Miles, Elkhart, Indiana, USA), oriented either transversely or longitudinally, and snap frozen in 2-methyl butane at $-80^{\circ} \mathrm{C}$. Sections ( $15 \mathrm{~mm}$ thick) were cut on a cryostat and mounted on slides coated with $0.1 \%$ poly-L-lysine.

After preincubation with NHS, sections were exposed overnight at room temperature to KIT goat antiserum (Santa Cruz Biotechnology) diluted 1/500 in TBS-TX containing $1 \%$ NHS, rinsed in TBS, incubated for one hour at room temperature in TBS containing biotinylated donkey antigoat antiserum (Jackson) diluted $1 / 200 \quad(\mathrm{v} / \mathrm{v})$, followed by incubation for one hour at room temperature in a solution containing an avidin biotin complex (ABC Vectastain,Vector, Burlingame, California, USA). The immunoreaction was visualised with the chromogen 3,3'-daminobenzidine (Dako, Denmark).

Xgal histochemistry on $K I T^{W-l a c z} /+$ and $K I T^{{ }^{W-l a c z} / K I T}{ }^{W_{v}}$ transgenic mice was performed as previously reported. ${ }^{10}$

\section{In vitro studies}

\section{Organ bath experiments}

$K I T^{W} / K I T^{W v}$ mice, nNOS ${ }^{-/-}$, and control mice were killed by cervical dislocation. The perianal skin was excised and the anus and terminal rectum were quickly removed and placed in Krebs-Ringer's solution (KRS) (mmol/l: $\mathrm{NaCl} \mathrm{118.3,} \mathrm{KCl}$ 4.7, $\mathrm{MgSO}_{4}$ 1.2, $\mathrm{KH}_{2} \mathrm{PO}_{4}$ 1.2, $\mathrm{CaCl}_{2} 2.5, \mathrm{NaHCO}_{3} 25$, glucose 11.1). The solution was maintained at $37^{\circ} \mathrm{C}$ and aerated with a mixture of $95 \% \mathrm{O}_{2}$ and $5 \% \mathrm{CO}_{2}$.

A ring segment comprising $2 \mathrm{~mm}$ of the terminal rectum, including the anal orifice, was removed and opened. One circular muscle strip was cut and mounted in an organ bath (25 ml) filled with Krebs-Ringer's solution. Each muscle strip was connected to a metal rod and attached to a strain gauge transducer (Statham UC2, Quincy, Massachusetts, USA) for continuous recording of isometric tension. A resting force of $600 \mathrm{mg}$ was applied on the strips. Platinum electrodes were placed parallel to the tissue in the organ baths for application of electrical field stimulation. Electrical impulses (0.25$8.0 \mathrm{~Hz}, 1 \mathrm{~ms}$, pulse trains lasting 10 seconds) were provided by a Grass stimulator (Quincy) and a direct current amplifier. Non-adrenergic non-cholinergic (NANC) conditions were obtained by addition of $1 \mu \mathrm{mol} / \mathrm{l}$ atropine and $1 \mu \mathrm{mol} / \mathrm{l}$ guanethidine. After each contraction, the muscle strips were washed at least three times every five minutes.

In a first series of experiments, the effect of electrical stimulation was investigated and the effect of sodium nitroprusside (SNP $2.5 \mathrm{mmol} / \mathrm{l}$ ) and 5'-adenosine triphosphate (ATP $1.0 \mathrm{mmol} / \mathrm{l}$ ) were tested on circular muscle strips of murine IAS.
In a second series, the effects of N-nitro-L-arginine methyl ester (L-NAME $200 \mu \mathrm{mol} / \mathrm{l}$ ), the blocker of neuronal conductance tetrodotoxin $(2.0 \mu \mathrm{mol} / \mathrm{l})$, the blocker of $\mathrm{P}_{2}$ purinergic receptors suramin $(100 \mu \mathrm{mol} / \mathrm{l})$, and the combination of L-NAME and suramin were investigated on the responses to electrical impulses, to ATP $(1.0 \mathrm{mmol} / \mathrm{l})$, and to SNP ( $2.5 \mathrm{mmol} / \mathrm{l})$. L-NAME and suramin were added at least 20 minutes before the experiments.

\section{In vivo studies}

\section{Anorectal manometry}

Anorectal perfusion manometry was performed with a purpose built micromanometric anorectal catheter (outer diameter $0.8 \mathrm{~mm}$ ). The polyimide catheter incorporated an array of four side holes spaced $0.5 \mathrm{~mm}$ apart for measurement of anal sphincter pressure and basal pressure within the rectum. All side holes were perfused with sterile degassed water at a rate of $0.02 \mathrm{ml} / \mathrm{min}$. A polyethylene balloon was located proximally to the catheter to distend the rectum.

\section{Protocol}

Anorectal manometry was performed in anaesthetised mice. Mice were anaesthetised by intraperitoneal injection of a mixture of fentanyl citrate/fluanisone (Hypnorm; Janssen Pharmaceuticals, Beerse, Belgium) and midazolam (Dormicum; Roche, Mijdrecht, the Netherlands) at $0.07 \mathrm{ml} /$ $10 \mathrm{~g}$ (fentanyl $0.32 \mathrm{mg} / \mathrm{ml}$, fluanisone $10 \mathrm{mg} / \mathrm{ml}$, midazolam $5 \mathrm{mg} / \mathrm{ml}$ ). The catheter was positioned with at least two side holes straddling the anal sphincter high pressure zone and one side hole in the rectum. After positioning, basal anal sphincter pressure was recorded. Thereafter a polyethylene rectal balloon was introduced and positioned aside the manometric catheter. After an equilibration time of 15 minutes, graded rectal distensions of 10 seconds were applied using the polyethylene balloon $(0.25-0.40 \mathrm{ml}$ air insufflation) to evoke IAS relaxations. Consecutive rectal distensions were performed at one minute intervals and distensions were repeated three times at each volume. This distension protocol was repeated after addition of L-NAME ( $100 \mathrm{mg} / \mathrm{kg}$ intraperitoneally). ${ }^{16}$

In a separate series of experiments, rectal compliance was measured with a non-compliant (polyethylene) balloon with a maximum capacity of $0.45 \mathrm{ml}$. The balloon was fixed on a silicone catheter with a diameter of $1 \mathrm{~mm}$. This catheter was connected to a pressure transducer measuring intraballoon pressure during stepwise volume controlled distension (0.04$0.40 \mathrm{ml})$.

\section{Data analysis}

Basal IAS pressures were obtained from the baseline period preceding the distension protocol. A drop in anal sphincter pressure of at least $5 \mathrm{~mm} \mathrm{Hg}$, over 2-5 seconds, was identified as a RAIR. If rectal distension resulted in a RAIR, the amplitude of each relaxation was determined as the percentage decrease in basal pressure. This was calculated from the mean anal sphincter pressure before distension to the minimal anal sphincter pressure during the reflex. Duration of the reflex was measured from the onset of the relaxation until the pressure returned to its basal level.

\section{Chemicals}

All chemicals were from Sigma (St. Louis, Missouri, USA), unless otherwise stated. The following drugs were used: ATP, L-NAME, suramin, tetrodotoxin, and SNP. All chemicals were dissolved in distilled water and diluted in Krebs-Ringer solution to the stated final concentration. 

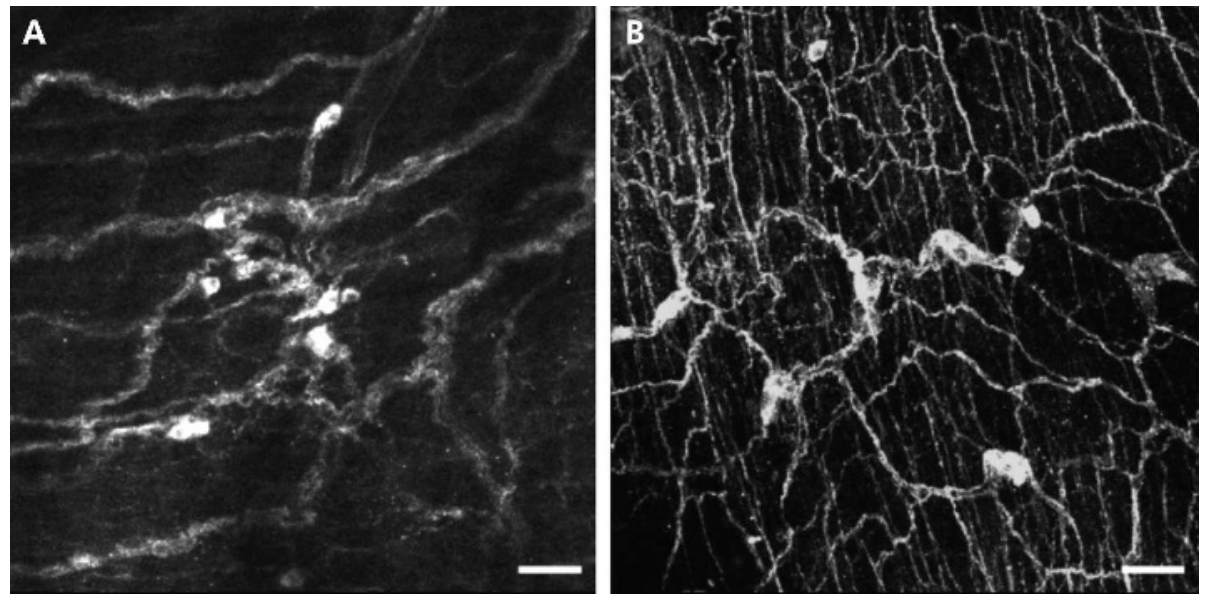

Figure 1 Neuronal nitric oxide synthase (nNOS)-ir distribution in the anorectum of a $K I T^{W-l a c Z} / K I T^{W v}$ interstitial cells of Cajal deficient mouse. (A) An $8 \mu \mathrm{m}$ thick projection of the myenteric region, showing a few nNOS-ir myenteric neurones and numerous large nerve bundles. (B) A $16 \mu \mathrm{m}$ thick projection of the circular muscle layer and submucosal plexus, showing abundant nNOS-ir nerve fibres in the circular muscle layer and submucosal nNOS-ir fibres and neurones. Orientation: oral, left; aboral, right. Scale bars $50 \mu \mathrm{m}$.

\section{Statistical analysis}

Group data are expressed as mean (SEM). Differences in data were evaluated using the Mann-Whitney $U$ test or the Wilcoxon signed ranks test were indicated. A p value of
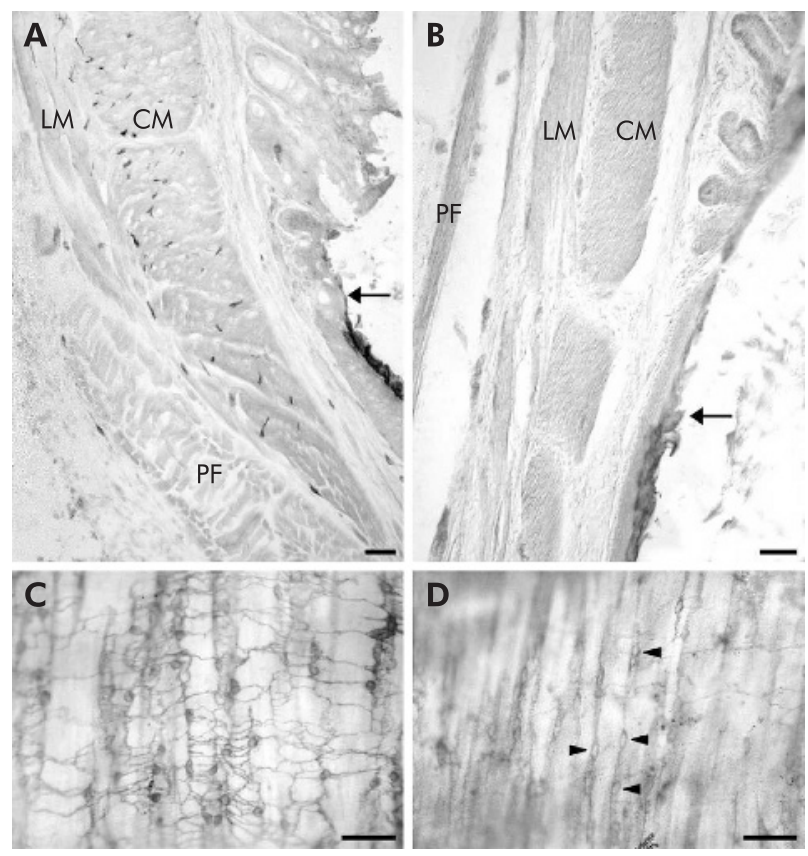

Figure 2 Distribution of KIT-ir interstitial cells of Cajal (ICC) in the internal anal sphincter (IAS) region of control $K I T W-$ lacZ $/+$ and ICC deficient $K I T{ }^{W-l a c Z} / K I T T_{v}$ mice. (A, B) Longitudinal sections across the IAS region of a control KIT ${ }^{W \text {-lacZ }} /+$ mouse $(A)$ and an ICC deficient $K I T T^{W-l a c Z} / K I T^{W_{v}}$ mouse (B). The arrows in the lumen indicate mucocutaneous transition. The various populations of KIT-ir ICC are abundant in the control (A) while KIT-ir ICC are essentially lacking in ICC deficient animals (B). (C, D) Whole mount preparations showing KIT-ir ICC in the submuscular plexus of a control KIT W-lacZ/+ mouse (C) and an ICC deficient KIT ${ }^{W-l a c Z} / K I T^{W_{v}}$ mouse (D). KIT-ir ICC form chains running parallel to the circular muscle layer and interconnected by multiple processes in the submuscular plexus of a control KIT ${ }^{W-l a c z} /+$ mouse (C) while in the submuscular plexus of an ICC deficient KIT W-lacZ/KIT Wv mouse (D) chains of KIT-ir ICC appeared only faintly stained (arrowheads) and lack most longitudinal interconnecting processes. Orientation in (C, D): oral at left, aboral at right. CM, circular muscle layer; $L M$, longitudinal muscle layer; PF, striated muscle of the pelvic floor. Scale bars $50 \mu \mathrm{m}$.
$<0.05$ was considered statistically significant. The $n$ values reported refer to the number of animals used in each protocol.

\section{RESULTS}

Immunohistochemistry

nNOS-ir in the region of the IAS

In both control $\left(\right.$ KIT $^{\left.W^{-l a c Z} /+\right)}$ (not shown) and KIT ${ }^{\text {W-lacZ }} / K_{\text {IIT }}{ }^{W v}$ mice (fig 1A, B), a dense network of nNOS-ir nerve fibres was present in the circular and longitudinal muscle layers of the distal rectum, including the IAS. Within the intermuscular plane of the IAS, both nNOS-ir neurones and nerve bundles were present but myenteric ganglia contained fewer neurones and the nerve bundles were coarser when compared with the distribution in the proximal rectum (not shown). Conversely, the density of nNOS-ir nerve fibres and neurones of the

A 1 minute

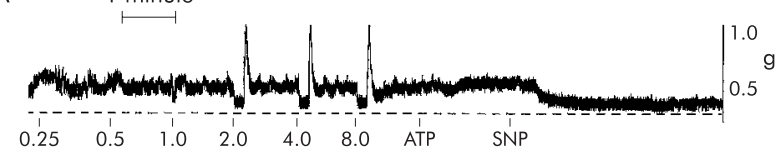

B
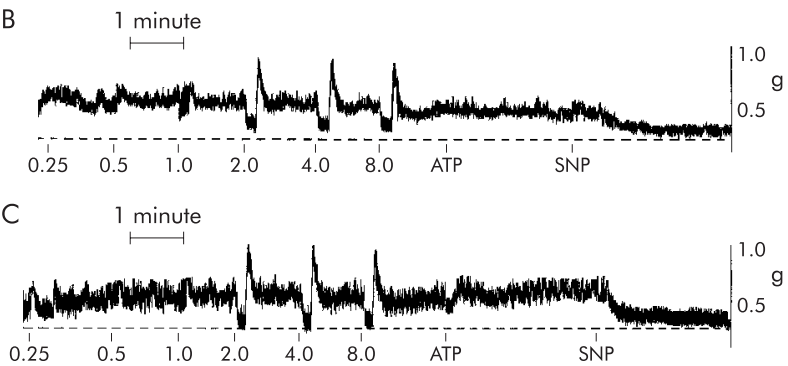

D 1 minute

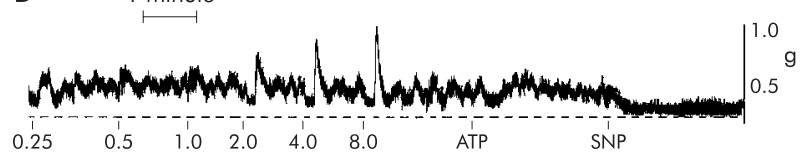

Figure 3 Representative recordings showing the non-adrenergic noncholinergic inhibitory responses to electrical impulses $(0.25-8.0 \mathrm{~Hz}$ $1 \mathrm{~ms}$, pulse trains lasting 10 seconds), 5'-adenosine triphosphate (ATP $1.0 \mathrm{mM}$ ), and sodium nitroprusside (SNP $2.5 \mathrm{mM}$ ) in muscle strips of a $K I T T^{W} /+$ control $(\mathrm{A}), K I T^{\mathrm{W}} / K I T^{\mathrm{W}}(\mathrm{B})$, neuronal nitric oxide synthase (nNOS) control (C), and $\mathrm{nNOS}^{-1-}$ mouse (D). 

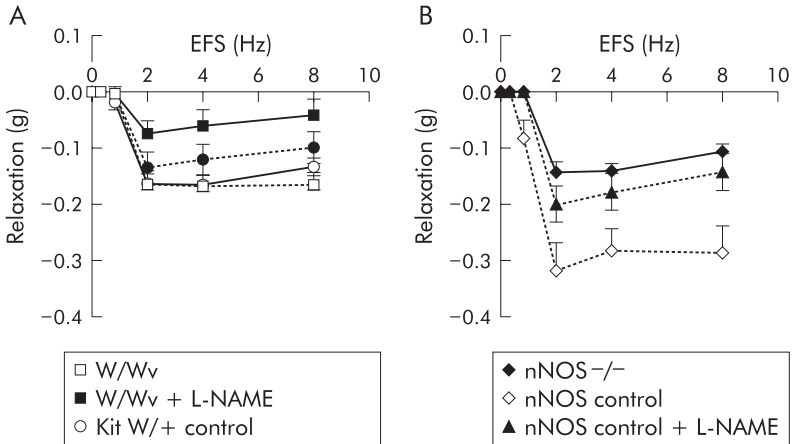

\section{$\square \mathrm{W} / \mathrm{Wv}$}

- W/Wv + L-NAME

$\circ$ Kit $W /+$ control

- Kit W/+ control + L-NAME

Figure 4 (A) Effect of N-nitro-L-arginine methyl ester (L-NAME $200 \mu \mathrm{mol} / \mathrm{I}$ ) on relaxations induced by electrical field stimulation (EFS) in $K I T^{W} / K I T^{W_{v}}$ and control mice. (B) Relaxations of internal anal sphincter muscle strips evoked by EFS in control mice and neuronal nitric oxide synthase deficient (nNOS ${ }^{-/-}$) mice. Addition of L-NAME $(200 \mu \mathrm{M})$ reduced relaxations of wild-type muscle strips. Values are mean (SEM) ( $n=6 ; p<0.001$, Wilcoxon signed ranks test).

submucosal plexus within the region of the IAS was similar to the proximal rectum.

\section{KIT-ir in the region of the IAS}

In controls (fig 2A), spindle shaped KIT-ir ICC were present in both muscle layers, parallel to smooth muscle cells. Stellate KIT-ir ICC were abundant surrounding the myenteric ganglia. At the level of the submuscular plexus, KIT-ir ICC formed chains parallel to the circular muscle layer. These chains were connected to each other by numerous delicate longitudinally processes. ICC at the submuscular plexus exhibited a weaker KIT-ir compared with the other populations of KIT-ir ICC and were best viewed on whole mounts (fig 2C). In the jejunum of the same animals, KIT-ir was detected in ICC-MP and ICCDMP, as expected (not shown).

In ICC deficient animals mice, KIT-ir ICC were lacking in the muscle layers and around the myenteric ganglia (fig 2B) while faint KIT-ir ICC at the level of the submuscular plexus were still present (fig 2D). However, they were less abundant and apparently lacked the normal branching pattern (compare with fig 2C). In the jejunum of these animals, a few ICCDMP exhibited weak KIT-ir, as expected in these ICC deficient animals (not shown). Due to the extreme lack of KIT expressing ICC in the region of the IAS of ICC deficient animals, no quantification was attempted.

\section{Xgal histochemistry in KIT W-lacZ/KIT Wv}

While Xgal histochemistry readily detected nuclei of KIT expressing ICC-DMP in the jejunum, no Xgal deposit was observed in the proximal rectum, or in the region of the IAS (not shown).

\section{Organ bath studies}

Involvement of NO in the inhibitory innervation of the IAS

In the presence of atropine and guanethidine, electrical stimulation $(0.25-8.0 \mathrm{~Hz}, 1 \mathrm{~ms}$, pulse trains lasting $10 \mathrm{sec}-$ onds) induced a frequency dependent relaxation of circular muscle strips of the murine IAS during the period of stimulation followed by an off contraction (fig 3A, C). Maximal relaxation of $K I T^{W} /+$ controls was obtained at $4 \mathrm{~Hz}$ $(0.16(0.05) \mathrm{g})$ (fig $4 \mathrm{~A})$ and in nNOS controls at $2 \mathrm{~Hz}(0.32$ $(0.14) \mathrm{g}$ ) (fig $4 \mathrm{~B}$ ). The resting (active) tone of the muscle strips of $K I T^{W /}+$ controls $(0.5 \mathrm{~g}), K I T^{W} / K I T^{W v}$ mice $(0.5 \mathrm{~g})$, nNOS controls $(0.6 \mathrm{~g})$, and $\mathrm{nNOS}^{-/-}$mice $(0.6 \mathrm{~g})$ were comparable.

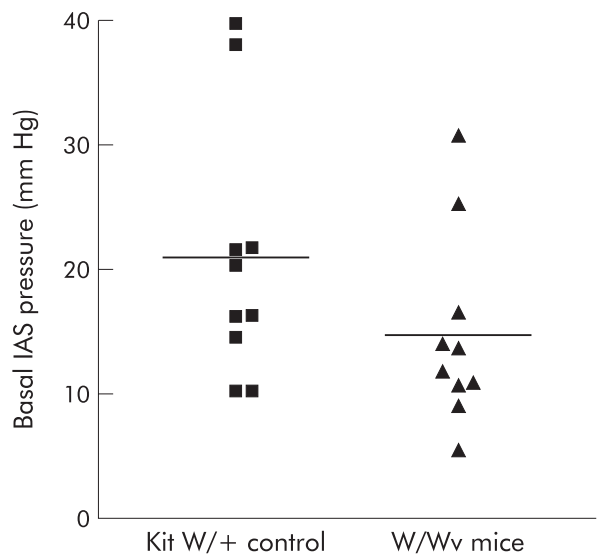

Figure 5 Basal internal anal sphincter (IAS) pressure of $\mathrm{KIT}^{\mathrm{W}} /+$ control mice and $K I T^{W} / K I T^{W_{v}}$. Horizontal lines represent mean values $(n=10$; NS).

\section{A}

Air volume (ml)

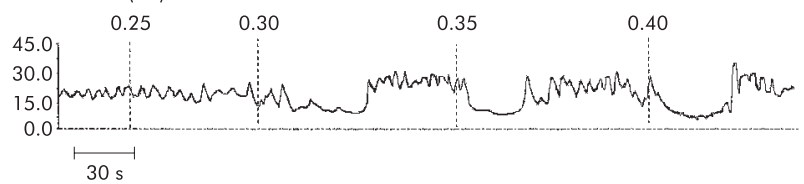

B

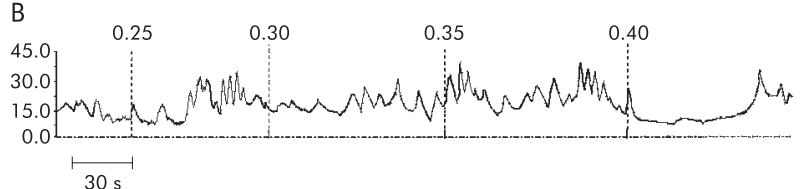

Figure 6 Representative in vivo rectoanal manometry recordings from a $K I T^{W} /+$ control $(\mathrm{A}), K I T^{W} / K I T^{W v}(\mathrm{~B})$, and neuronal nitric oxide synthase deficient (nNOS ${ }^{-1}$ ) mouse (C). Clear rectoanal inhibitory reflexes (RAIRs) are observed on incremental volumes of air insufflated $\left(0.25-0.40 \mathrm{ml}\right.$, as indicated) in $K I T^{W} /+$ controls. In $K I T^{W} / K I T^{W v}$ mutant mice, aberrant RAIRs are only observed on distension volumes of 0.40 $\mathrm{ml}$. Clear RAIRs are also seen in $\mathrm{nNOS}^{-/-}$mice but the amplitude of the RAIR is lower in $\mathrm{nNOS}^{-1-}$ mice compared with nNOS controls.

Both relaxation and the off contraction were abolished by tetrodotoxin, a blocker of neuronal conductance. SNP induced sustained relaxation $(0.15$ (0.01) g for control mice) of IAS muscle strips. Relaxation to SNP was resistant to tetrodotoxin. In contrast with SNP, ATP failed to relax the IAS preparation (fig 3).

\section{Effect of L-NAME in control mice}

Inhibition by L-NAME reduced relaxations in KIT ${ }^{W} /+$ controls $(n=8$, fig $4 A$ ) and in nNOS control mice $(n=6$, fig $4 \mathrm{~B})(\mathrm{p}<0.001)$. L-NAME had no effect on relaxations to SNP. The combination of L-NAME and suramin did not further reduce relaxations $(\mathrm{n}=4, \mathrm{p}=0.19)$ (data not shown).

Studies in $\mathrm{nNOS}^{-/-}$mice

To further evaluate the role of nitrergic neurotransmission in the relaxation of the IAS, mice deficient in nNOS were 


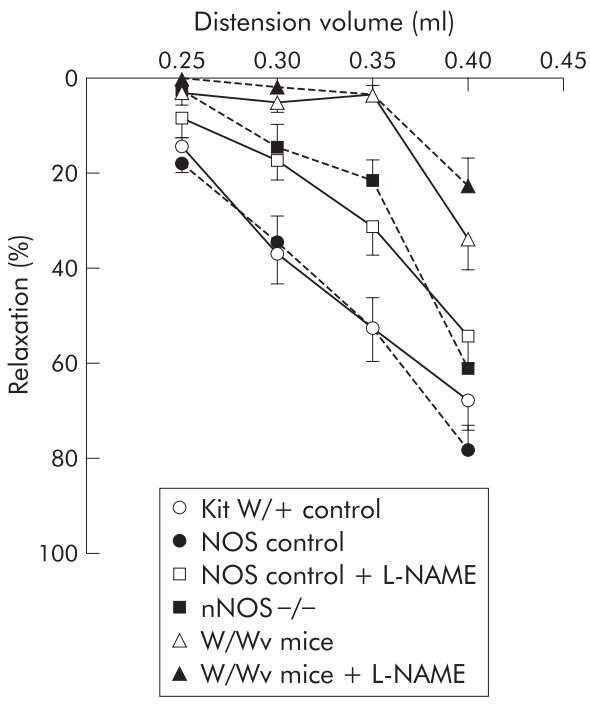

Figure 7 Amplitude of the rectoanal inhibitory reflex (RAIR) in neuronal nitric oxide synthase deficient ( $\mathrm{nNOS}^{-1-}$ ) mice and $K I T^{W} / K I T \mathrm{Wv}_{v}$ is significantly decreased compared with nNOS control mice and $K I T T^{\mathrm{W}} /+$ control mice ( $n=10 ; p<0.05$, Wilcoxon signed ranks test). Treatment of wild-type mice with $\mathrm{N}$-nitro-L-arginine methyl ester (L-NAME $100 \mathrm{mg} / \mathrm{kg}$ intraperitoneally) reduced the occurrence of RAIR to a similar extent. Treatment of KIT ${ }^{W} / K I T^{W_{v}}$ with L-NAME $(100 \mathrm{mg} / \mathrm{kg}$ intraperitoneally) slightly reduced the occurrence of RAIR (NS). Values are mean (SEM).

studied. Electrical stimulation of the IAS of $\mathrm{nNOS}^{-/-}$mice and their respective controls induced a frequency dependent relaxation during the period of stimulation followed by an off contraction (fig 3D). However, relaxations were also significantly reduced in $\mathrm{nNOS}^{-/-}$deficient mice compared with their controls $(n=6 ; p<0.001)$ (fig $4 B$ ).

\section{Evaluation of the role of ICC in the inhibitory innervation of the IAS.}

We next determined the NANC inhibitory response of IAS tissue of $K I T{ }^{W} / K I T^{W v}$ mice. Electrical stimulation induced a frequency dependent relaxation of circular muscle strips of the murine IAS during the period of stimulation followed by an off contraction in KIT ${ }^{W} / K I T^{W v}$ mice (fig 3B). Maximal relaxation was obtained at $4 \mathrm{~Hz}(0.17(0.05) \mathrm{g}, \mathrm{n}=10)$ and did not differ from control mice $(0.16(0.05) \mathrm{g}, \mathrm{n}=10)$. In concert, the amplitude of the frequency dependent relaxations in KIT ${ }^{W} / K_{T}{ }^{W v}$ mice was similar to their controls (fig $4 \mathrm{~A}$ ). Inhibition by L-NAME reduced the relaxations in $K I T^{W} / K I T^{W v}$ mice $(\mathrm{n}=8 ; \mathrm{p}<0.001)$ (fig $\left.4 \mathrm{~A}\right)$.

\section{Anorectal manometry} Involvement of $\mathrm{NO}$ in the inhibitory innervation of the IAS

Basal IAS pressure in $K I T^{W} /+$ control mice was 21 (3) $\mathrm{mm} \mathrm{Hg}$ $(\mathrm{n}=10)$ (fig 5) and 21 (2) $\mathrm{mm} \mathrm{Hg}(\mathrm{n}=10)$ for nNOS control mice. Distension of the rectum elicited a volume dependent relaxation or RAIR. Both in $K I T^{W} /+$ controls (fig 6) and nNOS controls, the duration of the RAIR was independent of distension volume. Mean durations were 14 (1) and 13 (1) seconds, respectively.

\section{Effect of L-NAME in control mice}

Administration of intraperitoneal L-NAME to nNOS controls reduced significantly the relaxations $(\mathrm{p}<0.05)$ (fig 7$)$. In KIT ${ }^{W} /+$ control mice, a comparable reduction was seen after administration of L-NAME (results not shown).

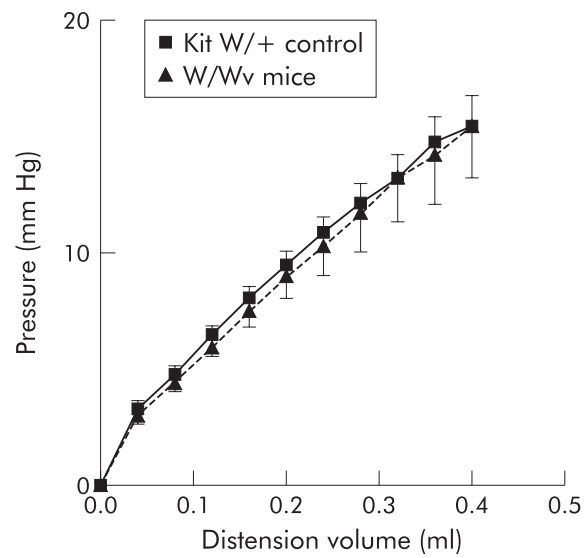

Figure 8 Rectal compliance in $K I T{ }^{W} / K I T^{W_{v}}$ was not different from $K I T^{W} /+$ control mice. Values are mean (SEM) $(n=6)$.

Studies in $\mathrm{nNOS}^{-/-}$mice

Basal IAS pressure in $\mathrm{NOS}^{-1-}$ mice was comparable to their nNOS controls (2l (3) and 21 (2) $\mathrm{mm} \mathrm{Hg}$, respectively). However, the amplitude of the RAIR was significantly lower in $\mathrm{nNOS}^{-1-}$ mice compared with nNOS controls $(\mathrm{p}<0.01)$ (figs 6, 7). Notably, the average duration of the RAIR was increased in $\mathrm{nNOS}^{-1-}$ mice compared with their controls (24 (3) and 15 (1) seconds, respectively; $p<0.01$ ).

\section{Evaluation of the role of ICC in the inhibitory} innervation of the IAS

Basal IAS pressure in KIT ${ }^{W} / K I T{ }^{W v}$ mice was comparable to controls (15 (2) and 21 (3) $\mathrm{mm} \mathrm{Hg}$ respectively, $\mathrm{n}=10$ ) (fig 5). Although the magnitude of the basal pressure was comparable, KIT ${ }^{W} / K I T^{W v}$ mice showed a more irregular basal sphincter pressure pattern with twitch contractions compared with controls. Distension of the rectum elicited a volume dependent relaxation in KIT ${ }^{W} / K I T{ }^{W v}$ mice. However, the RAIR amplitude was significantly attenuated in $K I T^{W} / K I T^{W v}$ mice compared with $K I T^{W} /+$ controls (figs 6, 7). At high distension volume, the RAIR could be observed in $K I T^{W} / K I T T_{v}^{W_{v}}$ mice although with variable duration and amplitude (figs 6, 7).

Administration of intraperitoneal L-NAME to $K I T^{W} / K I T^{W v}$ mice had no effect (fig 7).

Compliance in KIT $\mathrm{W} /+$ control mice and in KIT $\mathrm{W} /$ KIT $\mathrm{Wv}_{\mathrm{v}}$ mice

As the differences in RAIR could result from changes in rectal compliance, we also determined this parameter in both control and KIT ${ }^{W^{W}} / K I T T^{W_{v}}$ mice. Stepwise rectal volume distension revealed a similar increase in rectal pressure, demonstrating that rectal compliance was similar in control and $K I T^{W} / K I T^{W v}$ mice (fig 8).

\section{DISCUSSION}

NO is recognised as an important inhibitory neurotransmitter in the IAS. Previous studies showed that blockade of NO biosynthesis reduced the relaxation of muscle strips of the IAS induced by electrical stimulation and impaired the RAIR. ${ }^{35}$ In the present study, we extended the role of NO as an inhibitory neurotransmitter to the murine IAS: blockade of NO biosynthesis resulted in a reduction of both the in vitro and in vivo relaxation of the IAS. These findings were further corroborated by experiments in $\mathrm{nNOS}^{-1-}$ mice. Isolated muscle strips relaxed significantly less whereas the RAIR was impaired compared with controls. It should be emphasised that the IAS still relaxed in nNOS $^{-1-}$ mice and that blockade of NO biosynthesis in controls incompletely 
reduced electrical stimulation induced relaxation. These observations suggest that either nitrergic blockade was incomplete or, most likely, that another inhibitory neurotransmitter is involved. Previous studies in the rat IAS suggested ATP as a possible candidate. ${ }^{17}$ However, in our study, high concentrations of ATP failed to relax the IAS. In addition, suramin had no effect on relaxation, excluding the possible involvement of ATP. To what extent vasoactive intestinal polypeptide is involved remains to be investigated. ${ }^{5}$

ICC have been suggested to play a crucial role in normal gastrointestinal motility. In addition to their role as pacemaker cells, ${ }^{718}$ previous studies have suggested that ICC function as an intermediate between nerve fibres and smooth muscle cells mediating the nitrergic inhibitory neurotransmission in the stomach, LOS, and pyloric sphincter ${ }^{6-8}$ Due to the absence of the intramuscular-type of ICC, LOS muscle strips from $K I T^{W} / K I T^{W v}$ mice contracted rather than relaxed in response to electrical stimulation. ${ }^{7}$ Administration of L-NAME did not further change the response. ${ }^{7}$ As immunohistochemistry staining showed that the nitrergic innervation was intact, these findings indicated that ICC are important mediators of the nitrergic innervation in these tissues. In the present study, we failed to confirm this observation in the IAS. Electrical stimulation of the IAS of KIT ${ }^{W} / K I T{ }^{W v}$ mice relaxed to the same extent as those from controls. In addition, blockade of NO biosynthesis greatly reduced these relaxations, indicating that nitrergic innervation was intact. The latter was further confirmed by immunohistochemical staining. Our results argue against a role for ICC as intermediate between nitrergic nerves and smooth muscle cells. A similar conclusion was drawn by Sivarao and colleagues $^{19}$ who showed that relaxations of the LOS in response to swallowing or vagal stimulation was unaffected in $K I T^{W} / K I T^{W v}$ mice.

How can the discrepancy between our data and those of Ward and colleagues ${ }^{7}$ be explained? One could argue that the electrical stimulation parameters used $(1 \mathrm{~ms})$ were too intense, resulting in overflow of NO to the smooth muscle which might still elicit responses in tissue lacking ICC. ${ }^{20}$ However, in preliminary experiments, electrical stimulation with pulse trains of $0.5 \mathrm{~ms}$ failed to relax the IAS significantly. Furthermore, $1 \mathrm{~ms}$ pulse trains resulted in a normal frequency dependent response curve, excluding this possibility. Another explanation could be that the network of ICC of the IAS in contrast with the LOS and pylorus is unaffected in KIT ${ }^{W} / K I T^{W v}$ mice. However, similar to Ward et al, immunohistochemical assessment revealed that in $K I T^{W}$, KIT ${ }^{W v}$ and KIT ${ }^{\text {W-lacZ } / K I T^{W v}}$ mice, KIT-ir ICC were completely lacking in the muscle layers and around the myenteric ganglia. ${ }^{7}$ Alternatively, regional differences in the distance between nerve varicosities and smooth muscle cells, or differences in sensitivity of smooth muscle cells to NO, could be involved, but clearly this needs to be explored further.

Although we showed that the inhibitory innervation of the IAS in vitro was intact in ICC deficient mice, relaxation of the IAS in response to rectal distension was clearly diminished in $K I T^{W} / K I T^{W v}$ mice. As it is not clear whether stretch or tension receptors are involved in the triggering of the RAIR, one might argue that changes in compliance could affect the IAS response to rectal distension. Rectal compliance in ICC deficient mice was however identical to that of control mice. This is in contrast with Ward et al who described changes in gastric compliance in ICC deficient mice. ${ }^{21}$ This discrepancy can be explained by the fact that in the stomach, ICC have been shown to be involved in nitrergic and cholinergic neurotransmission, most likely contributing to the described changes in compliance in mice lacking ICC. In our experiments, however, we were unable to confirm the involvement of ICC in the nitrergic neurotransmission of the IAS, which may explain why compliance in the anorectal area is not altered. Our finding that the RAIR is strongly diminished in $K I T^{W} / K I T{ }^{W v}$ mice in the presence of an unaltered rectal compliance suggests the involvement of ICC in the triggering of the RAIR.

Theoretically, ICC could play a role in the neural pathway mediating the RAIR, either at the afferent limb in the detection of rectal distension or at the efferent part ${ }^{22}$ by mediating nitrergic neurotransmission. ${ }^{23}$ Our data favour involvement of ICC in the afferent limb, as both immunohistochemical and in vitro studies showed normal nitrergic neurotransmission in the IAS of $K I T^{W} / K I T^{W v}$ mice. One possible explanation could be that ICC act as mechanosensory receptors detecting rectal distension. Previous studies indeed showed that ICC make direct functional contact with intramuscular arrays of enteric nerves ${ }^{1422}$ and therefore could be involved in mechanical perception of distension. Alternatively, ICC may be required for the development of afferent nerves, especially as intramuscular arrays of vagal afferent fibres are significantly reduced in density in $K I T^{W} / K I T^{W v}$ mice compared with controls. This would suggest that abnormalities in the afferents secondary to the absence of a normal ICC network would underlie the impaired detection of stretch. However, the RAIR is considered to be mediated by a neural circuitry located within the enteric nervous system and, so far, no abnormalities in the enteric sensory neurones have been described in ICC deficient mice. To what extent the RAIR is impaired in KIT ${ }^{W} / K I T T^{{ }^{W v}}$ mice due to secondary changes in intrinsic sensory neurones or whether the ICC function as mechanoreceptors cannot be determined from our experiments.

Impaired or absent relaxation of the IAS hampers the evacuation of stool leading to severe chronic constipation. ${ }^{1}$ The typical example is Hirschsprung's disease characterised by aganglionosis of the distal gastrointestinal tract with subsequent absence of the RAIR and delayed passage of meconium. Similarly, delayed evacuation of meconium is also present in another subgroup of neonates with abdominal distension and feeding problems. ${ }^{24}$ However, gastrointestinal symptoms resolve soon after birth. The exact reason for this delayed evacuation of meconium is unclear. Interestingly, a study showed that delayed maturation of ICC may lead to transient defecation problems in neonates. ${ }^{24}$ As we showed that a deficiency of ICC impairs the RAIR, delayed maturation of ICC could be involved in the delayed passage of meconium in neonates. This hypothesis is currently being investigated.

In conclusion, we showed that the inhibitory innervation of the IAS and the RAIR are mediated by NO. Moreover, a normal RAIR requires an intact network of ICC in the IAS. Thus both loss of nitrergic innervation and deficiency of ICC lead to impaired anal relaxation and may play an important role in rectal evacuation disorders.

\section{ACKNOWLEDGEMENTS}

JMV is supported by grants from the National Fund for Scientific Research (Belgium), Fondation Medicale Reine Elisabeth (Belgium), and Fondation Universitaire David et Alice Van Buuren (Belgium). JMV is Senior Research Associate of the National Fund for Scientific Research (Belgium). TW is supported by grants from the Deutsche Forschungsgemeinschaft (DFG We 2366/3-1) and the Research Foundation of the University of Luebeck (J20-2003). The authors are indebted to Perrine Hague for the skilful technical assistance and to Huy Nguyen Tran for the assistance with the digital artwork preparation.

\footnotetext{
Authors' affiliations

F de Lorijn, M A Benninga, Department of Paediatric Gastroenterology and Nutrition, Emma Children's Hospital, Amsterdam, the Netherlands W J de Jonge, G E Boeckxstaens, Department of Gastroenterology and Hepatology, Academic Medical Centre, Amsterdam, the Netherlands
} 
T Wedel, J M Vanderwinden, Laboratoire de Neurophysiologie, Faculté de Médecine, Université Libre de Bruxelles, Brussels, Belgium

Conflict of interest: None declared.

\section{REFERENCES}

1 Loening-Baucke V, Pringle KC, Ekwo EE. Anorectal manometry for the exclusion of Hirschsprung's disease in neonates. J Pediatr Gastroenterol Nutr 1985;4:596-603.

2 Loening-Baucke V. Constipation in children. Curr Opin Pediatr 1994:6:556-61.

3 Stebbing JF, Brading AF, Mortensen NJ. Nitric oxide and the rectoanal inhibitory reflex: retrograde neuronal tracing reveals a descending nitrergic rectoanal pathway in a guinea-pig model. Br J Surg 1996;83:493-8.

4 Stebbing JF, Brading AF, Mortensen NJ. Nitrergic innervation and relaxant response of rectal circular smooth muscle. Dis Colon Rectum relaxant response

5 Rattan S, Chakder S. Role of nitric oxide as a mediator of internal anal sphincter relaxation. Am J Physiol 1992;262:G107-12.

6 Burns AJ, Lomax AE, Torihashi $S$, et al. Interstitial cells of Cajal mediate inhibitory neurotransmission in the stomach. Proc Natl Acad Sci U S A 1996;93:12008-13

7 Ward SM, Morris G, Reese L, et al. Interstitial cells of Cajal mediate enteric inhibitory neurotransmission in the lower esophageal and pyloric sphincters. Gastroenterology 1998;115:314-29.

8 Huizinga JD. Physiology and pathophysiology of the interstitial cell of Cajal: from bench to bedside. II. Gastric motility: lessons from mutant mice on slow waves and innervation, Am J Physiol Gastrointest Liver Physiol 2001;281:G1129-34.

9 Huizinga JD, Thuneberg L, Kluppel $M$, et al. W/kit gene required for interstitial cells of Cajal and for intestinal pacemaker activity. Nature 1995;373:347-9

10 Bernex F, De Sepulveda P, Kress C, et al. Spatial and temporal patterns of c-kit-expressing cells in WlacZ/+ and WlacZ/WlacZ mouse embryos. Development 1996;122:3023-33.

11 Nocka K, Tan JC, Chiu E, et al. Molecular bases of dominant negative and loss of function mutations at the murine c-kit/white spotting locus: W37, Wv, W41 and W. EMBO J 1990;9:1805-13.
12 Sibaev A, Franck H, Vanderwinden JM, et al. Structural differences in the enteric neural network in murine colon: impact on electrophysiology. Am J Physiol Gastrointest Liver Physiol 2003;285:G1325-34.

13 Vanderwinden JM, Rumessen JJ, Bernex F, et al. Distribution and ultrastructure of interstitial cells of Cajal in the mouse colon, using antibodies to Kit and Kit (W-lacZ) mice. Cell Tissue Res 2000;302:155-70.

14 Rumessen JJ, de Kerchove d'Exaerde A, Mignon S, et al. Interstitial cells of Cajal in the striated musculature of the mouse esophagus. Cell Tissue Res 2001;306:1-14

15 Ward SM, Burns AJ, Torihashi S, et al. Mutation of the proto-oncogene c-kit blocks development of interstitial cells and electrical rhythmicity in murine intestine. J Physiol 1994;480:91-7.

16 Calatayud S, Garcia-Zaragoza E, Hernandez C, et al. Downregulation of $\mathrm{nNOS}$ and synthesis of PGs associated with endotoxin-induced delay in gastric emptying. Am J Physiol Gastrointest Liver Physiol 2002;283:G1360-7.

17 De Luca A, Li CG, Rand MJ. Nitrergic and purinergic mechanisms and their interactions for relaxation of the rat internal anal sphincter. J Auton Pharmacol 1999; 19:29-37.

18 Der-Silaphet T, Malysz J, Hagel S, et al. Interstitial cells of cajal direct normal propulsive contractile activity in the mouse small intestine. Gastroenterology 1998; 114:724-36.

19 Sivarao DV, Mashimo HL, Thatte HS, et al. Lower esophageal sphincter is achalasic in $\mathrm{nNOS}^{-1-}$ and hypotensive in $\mathrm{W} / \mathrm{W}^{2}$ mutant mice. Gastroenterology 2001;121:34-42.

20 Sanders KM, Ward SM, Daniel EE. ICC in neurotransmission hard to swallow a lack of involvement. Gastroenterology 2002;122:1185-6.

21 Ward SM, Beckett EA, Wang X, et al. Interstitial cells of Cajal mediate cholinergic neurotransmission from enteric motor neurons. J Neurosci 2000;20:1393-403.

22 lino S, Ward SM, Sanders KM. Interstitial cells of Cajal are functionally innervated by excitatory motor neurons in the murine intestine. J Physiol 2004;556:521-30

23 Suzuki H, Ward SM, Bayguinov YR, et al. Involvement of intramuscular interstitial cells in nitrergic inhibition in the mouse gastric antrum. J Physiol 2003;546:751-63.

24 Kenny SE, Vanderwinden JM, Rintala RJ, et al. Delayed maturation of the interstitial cells of Cajal: a new diagnosis for transient neonatal pseudoobstruction. Report of two cases. J Pediatr Surg 1998;33:94-8.

\section{EDITOR'S QUIZ: GI SNAPSHOT}

\section{The radiologist made the diagnosis}

\section{Clinical presentation}

A 59 year old man was referred with a one year history of change in bowel habit and a low folate level. He had been opening his bowels more frequently but there was no associated abdominal pain or weight loss. Previous medical history included uveitis. Medication consisted of folic acid and he smoked 40 cigarettes a day. Physical examination was unremarkable. Initial blood tests revealed a normal full blood count, urea and electrolytes, liver and thyroid function, glucose, and $\mathrm{C}$ reactive protein $\mathrm{A}$ double contrast barium enema was performed (fig 1).

\section{Question}

In fig $\mathrm{l}$, what abnormality is demonstrated and what diagnostic procedure was then performed?

See page 1168 for answer

This case is submitted by:

J R Bebb

Department of Gastroenterology, Nottingham City Hospital, Nottingham, UK K H Latief

Department of Radiology, Nottingham City Hospital, Nottingham, UK

Correspondence to: Dr J R Bebb, Department of Gastroenterology, Nottingham City Hospital, Hucknall Rd, Nottingham NG7 1PB, UK; jamesbebb@doctors.org.uk

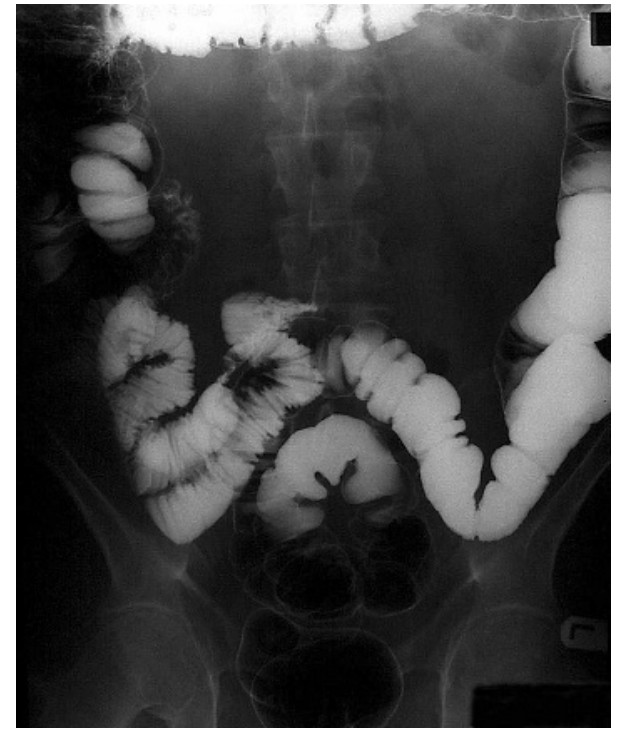

Figure 1 Double contrast barium enema. 